\title{
Article \\ Complete Genome Sequence of vB_EcoP_SU7, a Podoviridae Coliphage with the Rare C3 Morphotype
}

\author{
Shazeeda Koonjan ${ }^{1, *(D)}$, Callum J. Cooper ${ }^{2}$ and Anders S. Nilsson ${ }^{1}$ (D) \\ 1 Department of Molecular Biosciences, The Wenner-Gren Institute, Stockholm University, \\ 10691 Stockholm, Sweden; anders.s.nilsson@su.se \\ 2 School of Pharmacy, Pharmaceutical and Cosmetic Sciences, Faculty of Health Sciences and Wellbeing, \\ University of Sunderland, Sunderland SR13SD, UK; Callum.Cooper@sunderland.ac.uk \\ * Correspondence: shazeeda.koonjan@su.se
}

check for updates

Citation: Koonjan, S.; Cooper, C.J.; Nilsson, A.S. Complete Genome Sequence of vB_EcoP_SU7, a Podoviridae Coliphage with the Rare C3 Morphotype. Microorganisms 2021, 9, 1576. https://doi.org/10.3390/ microorganisms 9081576

Academic Editor: Igor V. Babkin

Received: 15 June 2021

Accepted: 22 July 2021

Published: 24 July 2021

Publisher's Note: MDPI stays neutral with regard to jurisdictional claims in published maps and institutional affiliations.

Copyright: (C) 2021 by the authors Licensee MDPI, Basel, Switzerland. This article is an open access article distributed under the terms and conditions of the Creative Commons Attribution (CC BY) license (https:/ / creativecommons.org/licenses/by/ $4.0 /)$.

\begin{abstract}
Enterotoxigenic Escherichia coli (ETEC) strains are an important cause of bacterial diarrheal illness in humans and animals. Infections arising from ETEC could potentially be treated through the use of bacteriophage (phage) therapy, as phages encode for enzymes capable of bacterial cell lysis. vB_EcoP_SU7 was isolated from the Käppala wastewater treatment plant in Stockholm, Sweden, and propagated on an ETEC strain exhibiting the O:139 serovar. Transmission electron microscopy confirmed that vB_EcoP_SU7 belongs to the Podoviridae family and has the rare C3 morphotype of an elongated head. Bioinformatic analyses showed that the genome was 76,626 base pairs long and contained 35 genes with predicted functions. A total of 81 open reading frames encoding proteins with hypothetical function and two encoding proteins of no significant similarity were also found. A putative tRNA gene, which may aid in vB_EcoP_SU7's translation, was also identified. Phylogenetic analyses showed that compared to other Podoviridae, vB_EcoP_SU7 is a rare Kuravirus and is closely related to E. coli phages with the uncommon C3 morphotype, such as ECBP2, EK010, vB_EcoP_EcoN5, and vB_EcoP_SU10. Phage vB_EcoP_SU7 has a narrow host range, infecting 11 out of the $137 \mathrm{E}$. coli strains tested, a latency period of $30 \mathrm{~min}$, a burst size of $12 \mathrm{PFU} /$ cell, and an adsorption rate of $8.78 \times 10^{-9} \mathrm{~mL} / \mathrm{min}$ five minutes post infection. With a limited host range and poor infection kinetics, it is unlikely that SU7 can be a standalone phage used for therapeutic purposes; rather, it must be used in combination with other phages for broad-spectrum therapeutic success.
\end{abstract}

Keywords: Kuravirus; C3 morphotype; Podoviridae; phage; genome annotation

\section{Introduction}

Escherichia coli is a common Gram-negative bacterium that is often found in the gastrointestinal tract of mammals and humans [1]. While there are a vast number of strains of E. coli that live as a normal part of the commensal microflora (estimated to be around $0.1 \%$ of the commensal microflora in humans) [2,3], there are a number of strains that are capable of causing disease [4]. Enterotoxigenic E. coli (ETEC) strains are among the major causative agents behind diarrheal diseases in low- and middle-income countries (often referred to as traveler's diarrhea) and in animal farming [5,6]. ETEC is characterized by its ability to produce heat-labile and/or heat-stable enterotoxins, which result in the intestinal lining secreting excess fluid and causing diarrhea [7].

ETEC infections are commonly treated with different antibiotics, such as fluoroquinolones (most used) and ciprofloxacin [6,8]. However, due to the ongoing widespread misuse of antibacterial agents, bacteria such as ETEC have developed resistance against commonly used antibiotics [8,9]. As a result, there has been renewed interest in using bacteria-specific viruses, otherwise known as phages, as an alternative to treat antibioticresistant infections since they encode for proteins associated with bacterial cell lysis. Infections caused by a single species, such as E. coli, as well as those caused by multiple 
bacteria have the potential to be treated with a cocktail comprised of different phage combinations [10], the efficacy of which is dependent on individual phage dosing, size, and virulence [11]. For phage therapy to be effective, new phages have to be identified and characterized. Understanding the genome composition and phylogeny of a phage can shed light on its ability to infect and adsorb using different bacterial receptors, such as the $\mathrm{O}$-antigen in E. coli species, as well as on their infection pharmacology and the development of phage-bacteria resistance. In this study, we present the isolation and genome annotation of vB_EcoP_SU7 (SU7), a Podoviridae coliphage with the C3 morphotype.

\section{Materials and Methods}

\subsection{Bacterial Strains and Growth Conditions}

The bacterial strains used for host range analyses were provided as follows: the E. coli ECOR standard reference collection [12] was kindly provided by Diarmaid Hughes and Dan Andersson (Uppsala University, Sweden) and the ETEC strains were provided by Martin Weiss Nielsen (Danmarks Tekniske Universitet Veterinærinstituttet, Kongens Lyngby, Denmark) and Åsa Sjöling (Karolinska Institute, Solna, Sweden). SU7 was propagated on the bacterial strain it was originally isolated on (ETEC exhibiting O:139 serovar; ETEC7). Bacterial cultures were grown in Miller's lysogeny broth (LB; Neogen, Lansing MI, USA) with shaking at 150 RPM or on tryptone yeast agar (TYA; Biolife Italiana, Milano, Italy) at $37^{\circ} \mathrm{C}$.

\subsection{Phage Propagation and Purification}

SU7 was previously isolated from the Käppala wastewater treatment plant located $15 \mathrm{~km}$ East of Stockholm, Sweden, in November 2016. For phage enrichments, fresh LB media was inoculated with $100 \mu \mathrm{L}$ of overnight bacterial cultures and allowed to grow to the mid-log phase at $37^{\circ} \mathrm{C}$ with shaking or until the optical density at $600 \mathrm{~nm}\left(\mathrm{OD}_{600}\right)$ was 0.6. SU7 was enumerated using the agar overlay $(\mathrm{OA})$ method with $65 \% w / v(22.75 \mathrm{~g} / \mathrm{L})$ TYA as previously described $[13,14]$. Concentrated stocks of SU7 were produced using a modified polyethylene glycol (PEG) precipitation protocol [15]. In brief, crude phage lysate suspensions were centrifuged at $3864 \times g$ for $10 \mathrm{~min}$ and the supernatant passed through a sterile $0.45 \mu \mathrm{m}$ syringe filter (Sarstedt Filtropur, Nümbrecht, Germany). Phages were precipitated by adding solid NaCl and PEG8000 (Acros Organics, Fisher Scientific, Schwerte, Germany) to the partially purified suspension to final concentrations of $1 \mathrm{M}$ and $10 \% w / v$, respectively, and then stored at $4{ }^{\circ} \mathrm{C}$ for two weeks. Following refrigeration, phages were centrifuged at $11,000 \times g$ for one hour at $4{ }^{\circ} \mathrm{C}$, the pellet re-suspended in $50 \mathrm{~mL}$ phosphate-buffered saline (PBS), $\mathrm{pH}$ 7.4, and the phage content determined using the OA method.

\subsection{Plaque Morphology Determination}

SU7 plaque morphology was determined using ETEC7 as the host bacterium and the OA method [14]. In short, SU7 phage stock was serially diluted 1:10 in PBS. Three mL of OA was inoculated with $100 \mu \mathrm{L}$ of overnight host bacterium culture (approximately $10^{8} \mathrm{CFU} / \mathrm{mL}$ ) and $100 \mu \mathrm{L}$ of $10^{9}$ serially diluted SU7. The OA was poured over the surface of a pre-prepared TYA plate and incubated for approximately $18 \mathrm{~h}$ at $37^{\circ} \mathrm{C}$. Plaques were imaged using a Samsung SM-G950U camera. Twenty diameters were calculated using ImageJ software [16].

\subsection{Host Range Analysis}

The host range of SU7 was determined using the spot test assay as previously described [17]. In brief, inoculated OA was prepared by adding $100 \mu \mathrm{L}$ of overnight bacterial culture to $3 \mathrm{~mL}$ of $65 \%$ TYA, which was gently swirled and poured over the surface of a pre-prepared TYA plate. A working solution of the SU7 phage was diluted in PBS to a final concentration of $10^{5}-10^{6}$ plaque-forming units (PFU) $/ \mathrm{mL}$ and the phage content was determined by the OA method. Prepared bacterial plates were then inoculated with 
approximately $10 \mu \mathrm{L}$ of the diluted SU7 phage suspension using a stamper. The spots were allowed to dry at room temperature, plates incubated at $37^{\circ} \mathrm{C}$ overnight, and then assessed for its ability to produce a plaque. Host-range experiments were replicated in triplicate unless otherwise stated in the text.

\subsection{Transmission Electron Microscopy (TEM)}

PEG purified SU7 $\left(1.1 \times 10^{11} \mathrm{PFU} / \mathrm{mL}\right)$ was negatively stained with $1 \% w / v$ uranyl acetate [18] and visualized on a TECNAI G2 Spirit Bio TWIN, 80 kV (FEI Company). Dimensions of eight SU7 virions were measured at 13,000 $\times$ magnification and analyzed with ImageJ [16].

\subsection{SU7 Infection Kinetics}

The latency period, burst size, and adsorption rate constant for SU7 were determined using the modified one-step growth curve protocol used by Koonjan et al. (2020) [19]. In brief, $50 \mathrm{~mL}$ of LB was inoculated with $50 \mu \mathrm{L}$ of ETEC7 and incubated at $37^{\circ} \mathrm{C}$ with shaking until the bacteria reached the mid-log phase $\left(\mathrm{OD}_{600} 0.6\right)$. Once $\mathrm{OD}_{600} 0.6$ was reached, the bacterial suspension was removed; the final volume of the bacterial suspension used for the experiment was $44.982 \mathrm{~mL}$. A total of $18 \mu \mathrm{L}$ of the SU7 phage stock $\left(1.50 \times 10^{10} \mathrm{CFU} / \mathrm{mL}\right)$ was added to the mid-log-phase bacteria (approximately $5.03 \times 10^{7} \mathrm{CFU} / \mathrm{mL}$ ) at a multiplicity of infection (MOI) of 0.12 and mixed by swirling $(\mathrm{T}=0)$. Aliquots of $1 \mathrm{~mL}$, withdrawn every five minutes for an experimental duration of $65 \mathrm{~min}$, were centrifuged at $6000 \times g$ for one minute. Using the supernatant, 1:10 serial dilutions in PBS were done to determine the phage content during each time point. All experiments were performed in triplicates. The adsorption rate constant was determined using the following formula shown below, where $N$ is the bacterial density, $P_{o}$ and $P$ are the starting and ending phage titers, $k$ is the adsorption rate constant, and $t$ is the time in minutes over which adsorption occurs:

$$
k=-\ln (P / P o) / N t
$$

It should be noted that the adsorption rate constant was determined using only two time points ( $\mathrm{T}=0$ and $\mathrm{T}=5)$. The burst size was calculated by dividing the phage titer after the first burst (approximately at $35 \mathrm{~min}$ ) with the number of adsorbed phages (initial phage concentration at $\mathrm{T}=0$ minus phage concentration at $\mathrm{T}=5$ ).

\subsection{Phage DNA Extraction}

SU7 DNA was extracted from suspensions containing a minimum of $1 \times 10^{8} \mathrm{PFU} / \mathrm{mL}$ using the Norgen Biotek phage DNA isolation kit (Nordic BioSite AB, Täby, Sweden) according to the manufacturing instructions but with an additional DNAse I treatment. Before carrying out the sequencing, the phage DNA concentration was quantified by fluorometry on a Qubit 2.0 (Invitrogen, Thermo Fisher, Stockholm, Sweden) and the purity assessed by gel electrophoresis.

\subsection{Genome Sequencing and Bioinformatics of the SU7 Genome}

SU7 genome library preparation and sequencing on the Illumina Miseq platform, with paired-end 300 base-pair (bp) reads using a V3 600-cycle kit, were carried out by Eurofins (Ebersberg, Germany). The 718,152 reads in the phage index were quality controlled using FastQC version 0.11.8 [20]. Reads were assembled and evaluated using SPAdes in careful mode [21] and QUAST version 4.5.4 [22], respectively. Open reading frames (ORFs) and genes were predicted using Prokka version 1.14.5 on the Galaxy@Pasteur platform and Glimmer3 prediction in the Geneious 6.1.8 software package [23-28]. Inferred amino acid sequences were compared against the National Center of Biotechnology Information (NCBI) non-redundant protein sequences database restricted to Caudovirales using the Basic Local Alignment Search Tool (BLAST) BLASTx software [29]. Hypothetical bacterial $\sigma^{70}$ and phage promoter regions were found using BPROM [30,31] and PhagePromoter on the Galaxy@GalaxyDockerBuild platform [25,32,33], respectively. Rho-independent termina- 
tors were found using the ARNold web server [34,35]. Ribosomal binding sites (RBS) were identified based on the Shine-Dalgarno sequence AGGAGG (mismatches allowed included AAAA, AAGG, AGAGAGA, AGGA, AGGAGA, AGGG, GAGA, GAGG, GAGGA, GCGG, GGA, GGAA, GGAG, GGAGA, GGAGG, and GGGAA) in the untranslated regions approximately 5-15 nucleotides upstream of an identified ORF start codon [36,37]. Genomic guanine-cytosine (GC) content was found using the European Molecular Biology Open Software Suite (EMBOSS) geecee program $[38,39]$ and tRNA genes were detected using ARAGORN version 1.2.41 [40,41]. PhageTerm on the Galaxy@Pasteur platform was used to determine the genome termini of SU7 $[42,43]$.

\subsection{Phylogenetic Tree Construction}

Phylogenetic analyses of the SU7 genome were conducted using complete nucleotide sequence alignments. Sequences for whole genomes were obtained from the NCBI genome databases (Table 1). The genome nucleotide sequence of SU7 was aligned against genomes showing E-values $=0$ in discontinuous MegaBLAST searches against the nucleotide collection databases restricted to Caudovirales phages. Alignments were made in ClustalW with the default setting within the Mega-X software and in MAUVE version 20150226 with default settings [44-46]. An unrooted neighbor-joining phylogenetic tree was constructed using Mega-X with default settings. No outgroup was used for tree construction. Node confidence was evaluated using bootstrap testing based on 500 random re-samplings.

Table 1. Genome nucleotide comparison of SU7 and the Kuraviruses presenting the C3 morphotype.

\begin{tabular}{|c|c|c|c|c|c|c|c|}
\hline Phage & $\begin{array}{l}\text { Genome } \\
\text { Size (bp) }\end{array}$ & $\begin{array}{c}\text { GC } \\
\text { Content }\end{array}$ & $\begin{array}{l}\text { No. of } \\
\text { Genes }\end{array}$ & $\begin{array}{c}\text { E- } \\
\text { Value }\end{array}$ & $\begin{array}{l}\text { Identity } \\
(\%)\end{array}$ & $\begin{array}{c}\text { Query } \\
\text { Cover (\%) }\end{array}$ & Accession \\
\hline Escherichia phage ECBP2 & 77,315 & 42.4 & 121 & 0 & 93.88 & 83 & JX415536.1 \\
\hline Escherichia phage EK010 & 78,078 & 42.1 & 117 & 0 & 93.09 & 89 & LC553734.1 \\
\hline Escherichia phage vB_EcoP_EcoN5 & 76,083 & 42.1 & 128 & 0 & 91.26 & 54 & MN715356.1 \\
\hline Escherichia phage vB_EcoP_SU10 & 77,327 & 42.1 & 125 & 0 & 89.77 & 63 & KM044272.1 \\
\hline Escherichia phage PGN6866 & 78,549 & 42.3 & 41 & 0 & 88.69 & 63 & MT127620.1 \\
\hline Escherichia phage MN03 & 77,187 & 42.2 & 125 & 0 & 88.40 & 57 & MT129653.1 \\
\hline Escherichia phage O18-011 & 75,646 & 42.1 & 121 & 0 & 87.88 & 56 & LC553735.1 \\
\hline Escherichia virus phiEco32 & 77,554 & 42.3 & 129 & 0 & 87.37 & 61 & EU330206.1 \\
\hline Escherichia phage MN05 & 76,899 & 42.2 & 127 & 0 & 87.00 & 52 & MT129655.1 \\
\hline Escherichia phage ES17 & 75,007 & 42.1 & 123 & 0 & 86.25 & 56 & MN508615.2 \\
\hline Escherichia phage 172-1 & 77,266 & 42.0 & 130 & 0 & 86.20 & 62 & KР308307.1 \\
\hline Escherichia phage NJ01 & 77,448 & 42.0 & 109 & 0 & 86.18 & 61 & JX867715.1 \\
\hline Escherichia phage myPSH2311 & 68,712 & 42.4 & 89 & 0 & 85.67 & 45 & MG976803.1 \\
\hline Escherichia phage LAMP & 68,521 & 42.2 & 96 & 0 & 85.56 & 54 & MG673519.1 \\
\hline $\begin{array}{c}\text { Escherichia phage } \\
\text { vB_EcoP_WFI101126 }\end{array}$ & 77,307 & 42.1 & 136 & 0 & 85.45 & 58 & MK373770.1 \\
\hline Escherichia phage Paul & 79,429 & 42.0 & 134 & 0 & 85.18 & 58 & MN045231.1 \\
\hline Escherichia phage EP335 & 76,622 & 42.5 & 126 & 0 & 84.69 & 57 & MG748548.1 \\
\hline Escherichia phage KBNP1711 & 76,184 & 42.4 & 126 & 0 & 83.28 & 61 & KF981730.1 \\
\hline Shigella phage SGF2 & 76,964 & 42.3 & 119 & 0 & 77.85 & 61 & MN148435.1 \\
\hline Escherichia phage myPSH1131 & 76,163 & 42.3 & 97 & 0 & 75.90 & 44 & MG983840.1 \\
\hline
\end{tabular}




\section{Results and Discussion}

\subsection{SU7 Plaque Morphology, Virion Morphology, Infection Kinetics, and Host Range}

SU7 forms transparent, circular plaques approximately $1 \mathrm{~mm}$ in diameter $(1.4 \pm 0.3 \mathrm{~mm})$ upon a lawn of its host bacteria ETEC7 (Figure 1A). TEM confirms that SU7 is a phage belonging to the rare $\mathrm{C} 3$ morphotype of the Podoviridae family within the Caudovirales order. It has an elongated head, with a length of $134 \mathrm{~nm}(134 \pm 6 \mathrm{~nm})$ and width of $44 \mathrm{~nm}$ (44 $\pm 2 \mathrm{~nm}$ ), and a very short non-contractile tail, which could not be measured (Figure 1B). Occurring in less than $1 \%$ of Podoviridae virions, this rare morphotype has been observed among phages belonging to the Kuravirus genus (previously referred to as PhiEco32viruses) and include the E. coli phages vB_EcoP_SU10, Paul, and phiEco32 [47-50]. At an MOI of 0.12 , SU7 has a latency period of $30 \mathrm{~min}$ (defined as the time from the addition of phages to a significant rise in phage concentration) and a burst size of $12 \mathrm{PFU} /$ cell (Figure 2 and Supplementary Figure S1). The adsorption rate constant five minutes post infection was determined to be $8.78 \times 10^{-9} \mathrm{~mL} / \mathrm{min}$. C3 phages with larger elongated heads theoretically would have smaller plaque morphology (presumably due to the fact that larger virions would diffuse more slowly through the OA compared to phages with smaller heads) as well as lower virulence and inferior infection kinetics [51,52]. Morphology-based and infection kinetic assumptions of SU7 alludes that, like other C3 phages, it would not be an ideal standalone candidate for phage therapy as it is not very virulent, has a long latency period, and poor adsorption $[51,53,54]$.
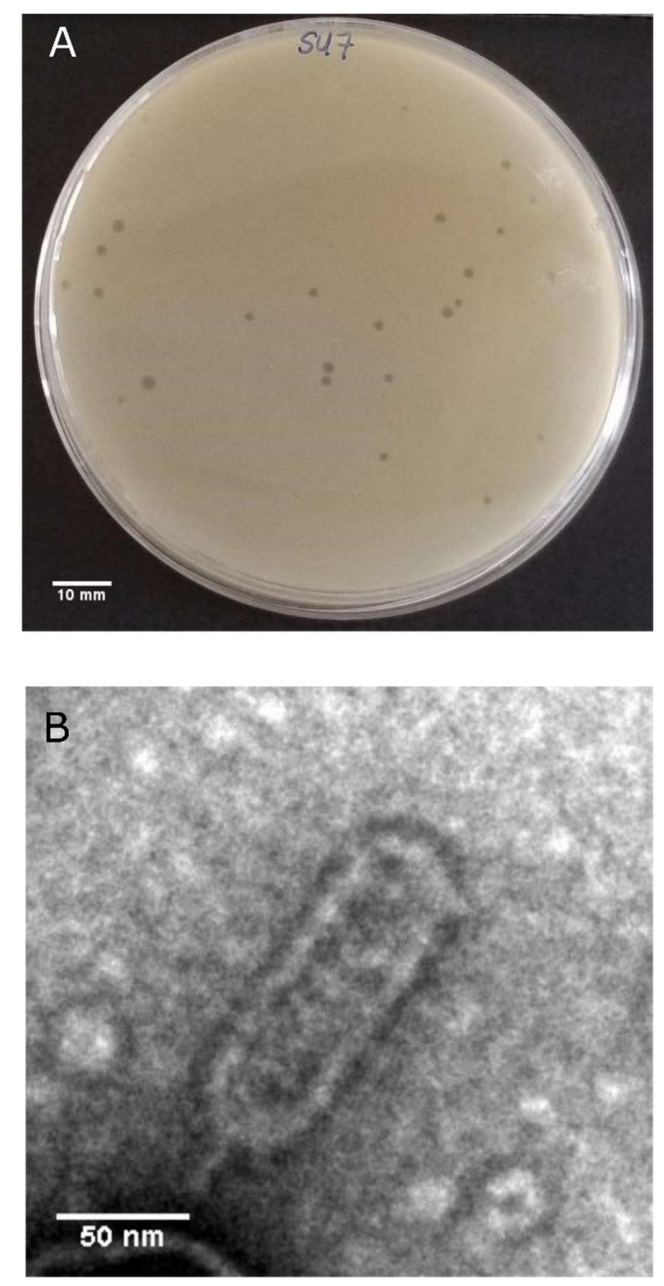

Figure 1. (A) Plaque morphology of SU7. Phages were cultured on ETEC7 forming $1 \mathrm{~mm}$ clear transparent plaques $(1.4 \pm 0.3 \mathrm{~mm}$ in diameter). (B) Transmission electron microscope micrograph of negatively stained phage SU7 at 13,000 $\times$ magnification. SU7 has an elongated head with a length of $134 \mathrm{~nm}(134 \pm 6 \mathrm{~nm})$ and a width of $44 \mathrm{~nm}(44 \pm 2 \mathrm{~nm})$. 


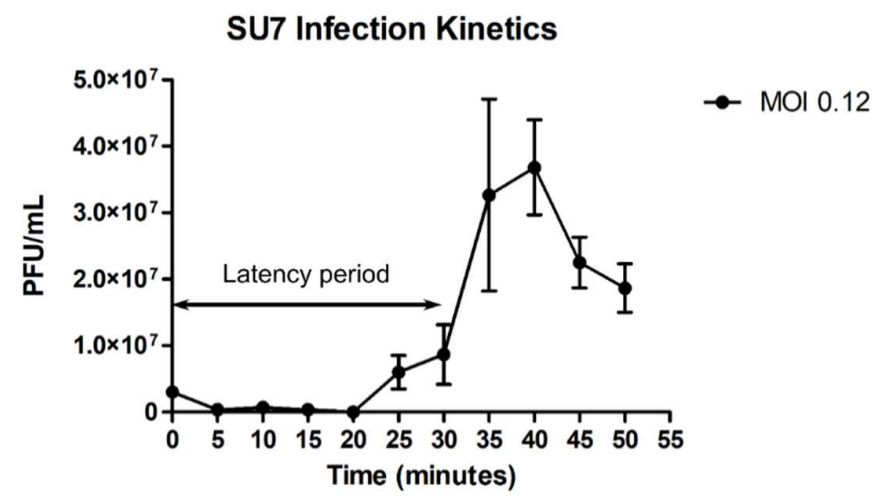

Figure 2. One-step growth curve of phage SU7 infecting bacterial ETEC7 at an MOI of 0.12. After one round of infection, SU7 has a latency period of $30 \mathrm{~min}$, a burst size of $12 \mathrm{PFU} /$ cell, and an adsorption rate constant of $8.78 \times 10^{-9} \mathrm{~mL} / \mathrm{min}$ five minutes post infection. Data points represent the mean of three independent experiments and error bars represent the standard error of each run.

When tested against 137 E. coli strains, phage SU7 showed a narrow host range, infecting 11 out of $137(8 \%)$ test strains (Supplementary Figure S2). Only the host strain ETEC7 displayed confluent lysis. Despite having 90\% shared identity (Table 1), C3 phage vB_EcoP_SU10 was capable of lysing 30 out of $72(42 \%)$ of the ECOR collection [51], whereas SU7 was only capable of lysing 9 out 72 (13\%). One possible explanation for SU7's narrow host range could be its host receptor. The most common phage-host receptor for Podoviridae coliphages is the O-polysaccharide antigen of the lipopolysaccharide layer [55-57], which is highly variable in the Enterobacter genus [58]. It should be noted that despite being a rapid, simple, and quantitative screen, single high titer spot testing to determine host range may fail to discriminate between a phage's ability to replicate within a host and its ability to kill the host strain, as well as result in an overestimation of phage host range and virulence $[51,59,60]$. From a therapeutic point of view, a narrow host range limits the ability of SU7 to a small set of potential ETEC pathogens [61].

\subsection{SU7 Genome Characterization}

Sequencing revealed SU7 has a double-stranded DNA genome of 76,626 bp in length and a GC content of $42 \%$.

Genome analyses revealed SU7 has 22 transcripts initiated at hypothetical E. coli $\sigma^{70}$ and phage promoters, eight putative rho-independent transcription terminator sites, 118 ORFs, and a putative tRNA ${ }^{\text {Arg }}$ gene. Many phages, including vB_EcoP_SU10, encode for this particular tRNA as way of compensating for low levels of host tRNA and to boost their translation [62]. Putative function was assigned to $30 \%$ of the predicted ORFs, which were categorized as either proteins pertaining to DNA metabolism, lysis, or structure (Figure 3 and Supplementary Table S1), whereas 70\% matched hypothetical proteins or protein domains with no significant similarity. On average, Kuravirus phages with the C3 morphotype tend to have a double-stranded DNA genome with a size of 76,213 bp, which encodes for approximately 122 genes, and have a GC content of $42 \%$ (Table 1) [63]. The genome of SU7 did not contain a gene encoding phage RNA polymerase (RNAP), suggesting that the transcription of the phage genome is carried out by the host bacteria machinery only. The presence of phage-specific promoters found by the PhagePromoter program, on the other hand, suggests that the RNAP is modified to accept and utilize these phage promoters instead. In the case a phage RNAP cannot be found, an alternative sigma factor must be encoded by the phage [64]. It is possible that this alternative sigma factor can be found within the genome's $70 \%$, presenting as a hypothetical protein; however, functional studies are required to make this conclusion. Like other phages presenting the C3 morphotype, there is a lack of correlation between the size of SU7's genome and head length, as determined by TEM, which suggests that the length of SU7's DNA does not affect the elongation of it head [49]. 


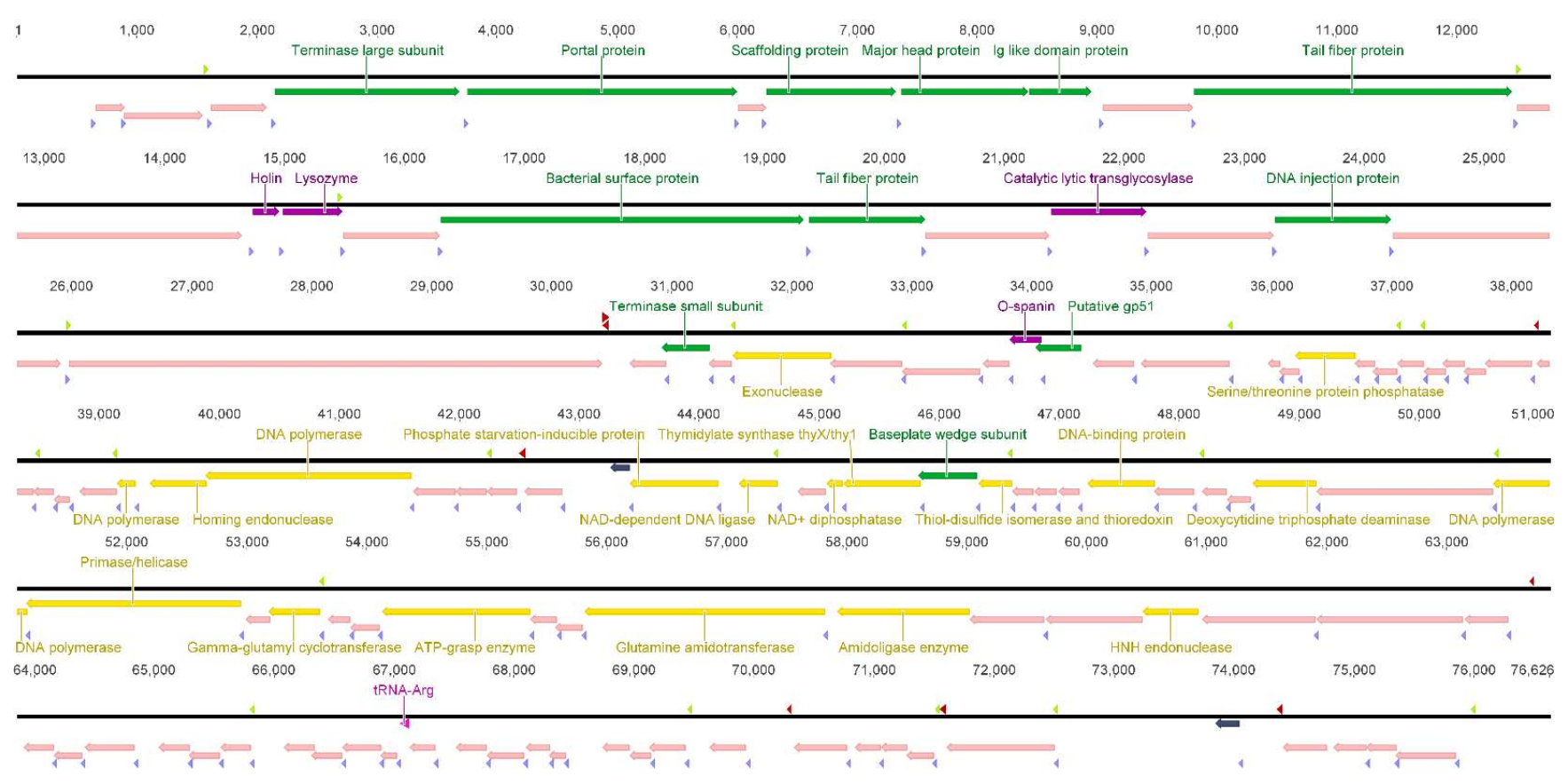

Figure 3. Genome organization with Prokka-predicted ORFs. Direction and annotation colored according to the function group of the genes: yellow, DNA metabolism; light pink, hypothetical proteins; dark gray, proteins with no significant similarity; green, structural proteins; dark purple, lysis related proteins; and pink, tRNA. Transcripts were identified by SoftBerry BROM and PhagePromoter on the Galaxy@GalaxyDockerBuild platform as starting at the promoter regions (light green) and ending at the rho-independent transcription terminators (red), which were identified using ARNold. Putative ribosomal binding sites (light purple) were identified in untranslated regions upstream of the ORFs. Genome visualization was obtained using Geneious software version 6.1.8. See Section 2 for references to the computer programs used.

PhageTerm predicted the SU7 genome termini ends in short direct terminal repeats (DTR). Like phage PhiEco32, it is possible that SU7 has a replication strategy whereby the formation of either circular or linear concatemeric DNA during infection results in the duplication of its genome ends; thus, the beginning and ending have the same sequence repetition [47]. Upon inspection, SU7's DTR region is only $53 \mathrm{bp}$, which is quite short in comparison to other Kuraviruses (most being $193 \mathrm{bp}$ ). It is possible that the DTR region of SU7 could be longer if more mismatches were allowed during the PhageTerm searches.

\subsection{Phylogenetic Analyses}

Whole genome MegaBLAST alignments of SU7's nucleotide sequence suggests that SU7 is most similar to E. coli phages ECBP2 (94\%), EK010 (93\%), vB_EcoP_EcoN5 (91\%), and vB_EcoP_SU10 (90\%) (Table 1 and Supplementary Figure S3).

All phages that bear genomic similarity to SU7 belong to the Kuravirus genus and are morphologically defined by an elongated head (the rare C3 morphotype). Phages belonging to Kuravirus share more than $61 \%$ DNA sequence and more than $69 \%$ protein homology [63]. This can be seen in the clustering pattern in SU7's phylogenetic analysis based on whole genome nucleotide sequences (Figure 4), suggesting that SU7 is also a Kuravirus. References to the Kuravirus phages in the phylogenetic analyses and their accession numbers can be found in Table 1 . 


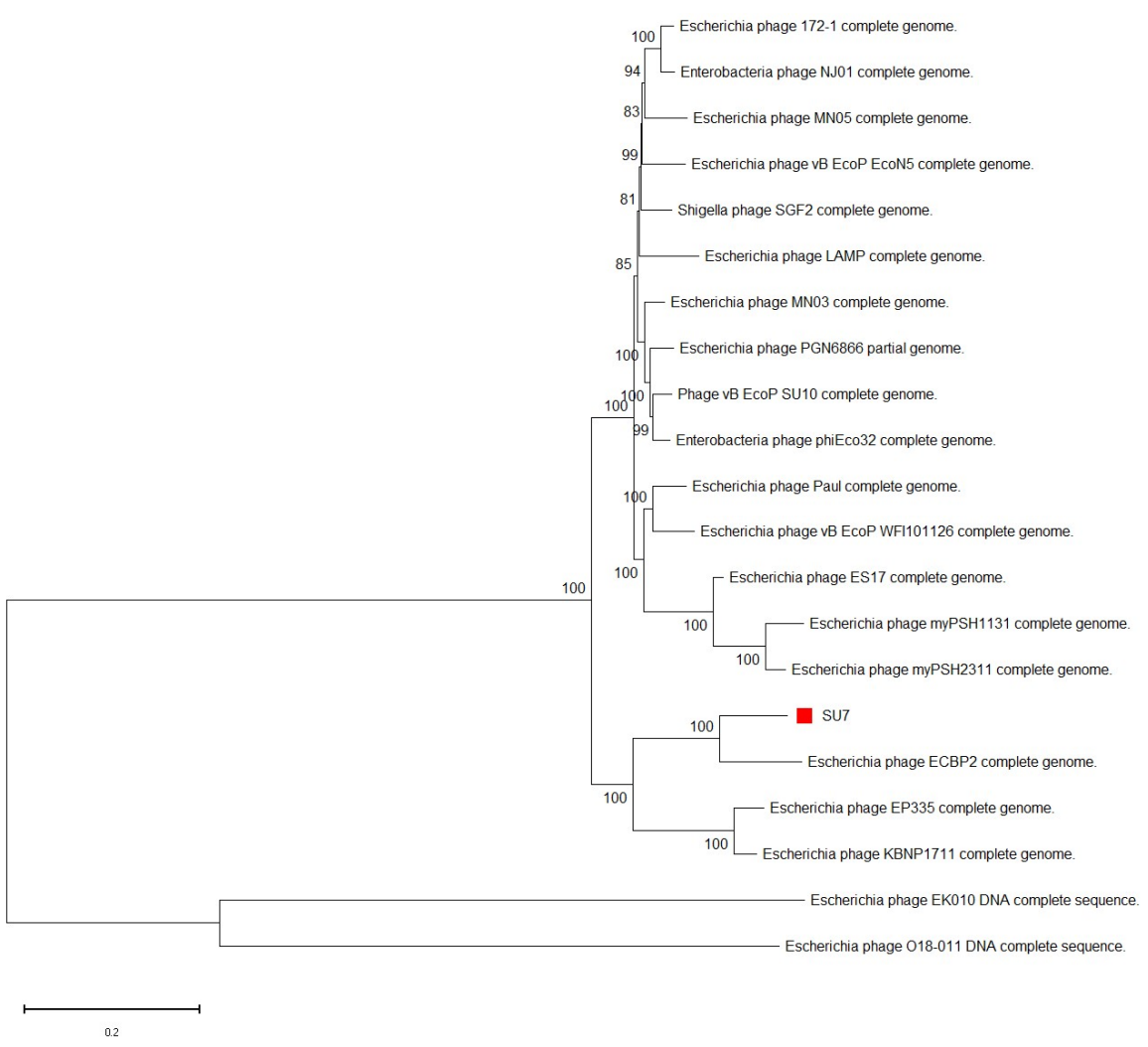

Figure 4. Neighbor-joining phylogenetic tree of phage SU7's whole genome nucleotide sequence in relation to other Kuraviruses. The sequence of SU7 and genome sequences showing an E-value of 0 in discontinuous MegaBlast searches against the nucleotide collection database at NCBI was aligned in ClustalW. The tree was constructed using Mega-X. The nodes depict the bootstrap values, which were calculated based on 500 replicates. The bar represents the number of nucleotide substitutions per site.

\section{Conclusions}

Due to their therapeutic potential, phages are ideal candidates to treat antibioticresistant infections, such as those arising from ETEC. However, many phages need to be isolated and their genomes characterized before they can be used therapeutically. We have isolated and characterized the genome of $\mathrm{vB}$ _EcoP_SU7, a Podoviridae phage with the rare C3 morphotype belonging to the Kuravirus genus. Successful phage therapy entails the phage(s) given must be virulent and rapidly reproduce, ideally having a short latency period and large burst size, be small in size to allow for better diffusion and site-directed dosage, and have a broad host range [11]. Given the limited host range, their size, and infection kinetics, it is unlikely that C3 phages such as SU7 can be used in a therapeutic way as a standalone treatment and would have to be given in combination with other smaller lytic phages. This research can, however, act as a stepping stone to delve further into C3 phage evolution and Kuravirus genomic diversity.

Supplementary Materials: The following are available online at https:/ /www.mdpi.com/article/10 $.3390 /$ microorganisms9081576/s1, Figure S1: One step growth curve of SU7 over an experimental duration of $65 \mathrm{~min}$, Figure S2: Host range analyses on phage SU7, Figure S3: Multiple genome alignment of SU7 and closely related Kuraviruses vB_EcoP_SU10, vB_EcoP_EcoN, ECBP2, and EK010 using MAUVE, Table S1: General features and functions of presumed genes from phage SU7.

Author Contributions: Conceptualization, S.K., C.J.C. and A.S.N.; A.S.N. and C.J.C. isolated phages from the wastewater treatment facility; S.K. and C.J.C. performed phage purification and propagation; C.J.C. performed phage DNA extraction and host-range experiments; S.K. performed TEM and phylogenetic analyses; S.K. and A.S.N. performed bioinformatics analyses; writing—original draft preparation, S.K.; writing-review and editing, C.J.C. and A.S.N.; visualization, S.K.; supervision, 
C.J.C. and A.S.N.; funding acquisition, A.S.N. All authors have read and agreed to the published version of the manuscript.

Funding: This work was supported by the Olle Engkvist Byggmästare Foundation under grant number 2015/419 and the Swedish Research Council for Environment, Agricultural Sciences and Spatial Planning (FORMAS) coordinated by the Animal Health and Welfare (ANIHWA) project within the European Research Area (ERA-NET) under grant number 221-2015-1984 as part of the project Bacteriophage Lysins as Alternatives to Antimicrobial Treatment (BLAAT) consortium.

Institutional Review Board Statement: Not applicable.

Informed Consent Statement: Not applicable.

Data Availability Statement: The datasets presented in this study can be found in online repositories. The genome has been submitted to NCBI and can be found under the GenBank accession number MZ342906.

Acknowledgments: We wish to thank the students of the "Analysis of Data from High-Throughput Molecular Biology Experiments" course at the KTH Royal Institute of Technology, Stockholm, Sweden, for doing the preliminary assembly of the SU7 genome, and Microbiology Master's student John Wilson at the Department of Molecular Biosciences, The Wenner-Gren Institute at Stockholm University, for aiding in the one-step growth curve experiments. We would also like to thank Chris Molenaar, of the Imaging Facility at Stockholm University (IFSU), for helping to capture TEM images of SU7.

Conflicts of Interest: The authors declare no conflict of interest.

\section{References}

1. Conway, T.; Krogfelt, K.A.; Cohen, P.S. The Life of Commensal Escherichia coli in the Mammalian Intestine. EcoSal Plus 2004, 1. [CrossRef]

2. Eckburg, P.B.; Bik, E.M.; Bernstein, C.N.; Purdom, E.; Dethlefsen, L.; Sargent, M.; Gill, S.R.; Nelson, K.E.; Relman, D.A. Diversity of the Human Intestinal Microbial Flora. Science 2005, 308, 1635-1638. [CrossRef]

3. Gao, Y.-D.; Zhao, Y.; Huang, J. Metabolic Modeling of CommonEscherichia coliStrains in Human Gut Microbiome. BioMed Res. Int. 2014, 2014, 1-11. [CrossRef] [PubMed]

4. Evans, D.J., Jr.; Evans, D.G. Classification of Pathogenic Escherichia coli According to Serotype and the Pro-duction of Virulence Factors, with Special Reference to Colonization-Factor Antigens. Rev. Infect. Dis. 1983, 5, S692-S701.

5. Bin Cha, S.; Na Yoo, A.; Lee, W.J.; Shin, M.K.; Jung, M.; Shin, S.W.; Cho, Y.W.; Yoo, H.S. Effect of Bacteriophage in Enterotoxigenic Escherichia coli (ETEC) Infected Pigs. J. Vet. Med. Sci. 2012, 74, 1037-1039. [CrossRef]

6. Enterotoxigenic E. coli (ETEC) I E. coli ICDC. Available online: https://www.cdc.gov/ecoli/etec.html (accessed on 31 May 2021).

7. Duan, Q.; Xia, P.; Nandre, R.; Zhang, W.; Zhu, G. Review of Newly Identified Functions Associated With the Heat-Labile Toxin of Enterotoxigenic Escherichia coli. Front. Cell. Infect. Microbiol. 2019, 9, 292. [CrossRef]

8. Begum, Y.A.; Talukder, K.A.; Azmi, I.J.; Shahnaij, M.; Sheikh, A.; Sharmin, S.; Svennerholm, A.-M.; Qadri, F. Resistance Pattern and Molecular Characterization of Enterotoxigenic Escherichia coli (ETEC) Strains Isolated in Bangladesh. PLoS ONE 2016, 11, e0157415. [CrossRef]

9. Ventola, C.L. The Antibiotic Resistance Crisis: Part 1: Causes and threats. Pharm. Ther. 2015, 40, $277-283$.

10. Chan, B.K.; Abedon, S.T.; Loc-Carrillo, C. Phage cocktails and the future of phage therapy. Futur. Microbiol. 2013, 8, 769-783. [CrossRef] [PubMed]

11. Nilsson, A.S. Phage therapy—constraints and possibilities. Upsala J. Med. Sci. 2014, 119, 192-198. [CrossRef]

12. Ochman, H.; Selander, R.K. Standard reference strains of Escherichia coli from natural populations. J. Bacteriol. 1984, 157, 690-693. [CrossRef] [PubMed]

13. Gratia, A. The Numerical Relation between Lysogenic Bacteria and the Phage Particles which they carry. Ann. Inst. Pasteur 1936, $57,652-676$.

14. Kropinski, A.M.; Mazzocco, A.; Waddell, T.E.; Lingohr, E.; Johnson, R.P. Enumeration of Bacteriophages by Double Agar Overlay Plaque Assay. In Bacteriophages; Martha, R.J., Clokie, A.M.K., Eds.; Springer: Berlin/Heidelberg, Germany, 2009; Volume 501, pp. 69-76.

15. Sambrook, J.; Russell, D.W. Precipitation of Bacteriophage $\lambda$ Particles from Large-scale Lysates. Cold Spring Harb. Protoc. 2006, 2006, 3966. [CrossRef]

16. Schneider, C.A.; Rasband, W.S.; Eliceiri, K.W. NIH Image to ImageJ: 25 years of image analysis. Nat. Methods 2012, 9, 671-675. [CrossRef] [PubMed]

17. Kutter, E. Phage Host Range and Efficiency of Plating. Adv. Struct. Saf. Stud. 2009, 501, 141-149. [CrossRef]

18. Broers, A.N.; Panessa, B.J.; Gennaro, J.F. High-resolution scanning electron microscopy of bacteriophages 3C and T4. Science 1975, 189, 637-639. [CrossRef] [PubMed] 
19. Koonjan, S.; Seijsing, F.; Cooper, C.J.; Nilsson, A.S. Infection Kinetics and Phylogenetic Analysis of vB_EcoD_SU57, a Virulent T1-Like Drexlerviridae Coliphage. Front. Microbiol. 2020, 11, 2439. [CrossRef]

20. Babraham Bioinformatics. FastQC v. 0.11.2. 2014. Available online: http://www.bioinformatics.babraham.ac.uk/projects/fastqc/ (accessed on 10 January 2020).

21. Bankevich, A.; Nurk, S.; Antipov, D.; Gurevich, A.A.; Dvorkin, M.; Kulikov, A.S.; Lesin, V.M.; Nikolenko, S.I.; Pham, S.; Prjibelski, A.D.; et al. SPAdes: A New Genome Assembly Algorithm and Its Applications to Single-Cell Sequencing. J. Comput. Biol. 2012, 19, 455-477. [CrossRef] [PubMed]

22. Gurevich, A.; Saveliev, V.; Vyahhi, N.; Tesler, G. QUAST: Quality assessment tool for genome assemblies. Bioinformatics 2013, 29, 1072-1075. [CrossRef] [PubMed]

23. Cuccuru, G.; Orsini, M.; Pinna, A.; Sbardellati, A.; Soranzo, N.; Travaglione, A.; Uva, P.; Zanetti, G.; Fotia, G. Orione, a web-based framework for NGS analysis in microbiology. Bioinformatics 2014, 30, 1928-1929. [CrossRef]

24. Seemann, T. Prokka: Rapid Prokaryotic Genome Annotation. Bioinformatics 2014, 30, 2068-2069. [CrossRef] [PubMed]

25. Afgan, E.; Baker, D.; Batut, B.; van den Beek, M.; Bouvier, D.; Čech, M.; Chilton, J.; Clements, D.; Coraor, N.; Gruning, B.A.; et al. The Galaxy platform for accessible, reproducible and collaborative biomedical analyses: 2018 update. Nucleic Acids Res. 2018, 46, W537-W544. [CrossRef] [PubMed]

26. Galaxy | Pasteur. Available online: https://galaxy.pasteur.fr/?tool_id=toolshed.pasteur.fr\%2Frepos\%2Ffmareuil\%2Fprokka\% 2Fprokka\%2F1.14.5\%2Bgalaxy0\&version=1.14.5\%2Bgalaxy0\&_identifer=m5chf8bbb2 (accessed on 31 May 2021).

27. Delcher, A.L.; Bratke, K.A.; Powers, E.C.; Salzberg, S. Identifying bacterial genes and endosymbiont DNA with Glimmer. Bioinformatics 2007, 23, 673-679. [CrossRef] [PubMed]

28. Geneious Prime. Available online: http://www.geneious.com/ (accessed on 7 April 2020).

29. Altschul, S.F.; Madden, T.L.; Schäffer, A.A.; Zhang, J.; Zhang, Z.; Miller, W.; Lipman, D.J. Gapped BLAST and PSI-BLAST: A new generation of protein database search programs. Nucleic Acids Res. 1997, 25, 3389-3402. [CrossRef] [PubMed]

30. Solovyev, V.; Salamov, A. Automatic Annotation of Microbial Genomes and Metagenomic Sequences. In Meta-Genomics and Its Applications in Agriculture, Biomedicine, and Envrionmental Studies; Nova Science Publishers: Hauppauge, NY, USA, 2011; pp. 61-78.

31. BPROM-Prediction of Bacterial Promoters. Available online: http://www.softberry.com/berry.phtml?topic=bprom\&group= programs\&subgroup =gfindb (accessed on 31 May 2021).

32. Sampaio, M.; Rocha, M.; Oliveira, H.; Dias, O. Predicting promoters in phage genomes using PhagePromoter. Bioinformatics 2019, 35, 5301-5302. [CrossRef]

33. Galaxy / Galaxy Docker Build. Available online: https://galaxy.bio.di.uminho.pt/?tool_id=toolshed.g2.bx.psu.edu\%2Frepos\% 2Fmartasampaio\%2Fphagepromoter\%2Fget_proms\%2F0.1.0\&version=0.1.0\&_identifer=axgcaazotdi (accessed on 31 May 2021).

34. Naville, M.; Ghuillot-Gaudeffroy, A.; Marchais, A.; Gautheret, D. ARNold: A web tool for the prediction of Rho-independent transcription terminators. RNA Biol. 2011, 8, 11-13. [CrossRef]

35. ARNold, Finding Terminators at I2BC-Web Server. Available online: http://rssf.i2bc.paris-saclay.fr/toolbox/arnold/ (accessed on 31 May 2021).

36. Shine, J.; Dalgarno, L. The 3'-Terminal Sequence of Escherichia coli 16S Ribosomal RNA: Complementarity to Nonsense Triplets and Ribosome Binding Sites. Proc. Natl. Acad. Sci. USA 1974, 71, 1342-1346. [CrossRef]

37. Ma, J.; Campbell, A.; Karlin, S. Correlations between Shine-Dalgarno Sequences and Gene Features Such as Predicted Expression Levels and Operon Structures. J. Bacteriol. 2002, 184, 5733-5745. [CrossRef]

38. Rice, P.; Longden, I.; Bleasby, A. EMBOSS: The European Molecular Biology Open Software Suite. Trends Genet. 2000, 16, $276-277$. [CrossRef]

39. EMBOSS: Geecee. Available online: https://www.bioinformatics.nl/cgi-bin/emboss/geecee (accessed on 31 May 2021).

40. Laslett, D.; Canback, B. ARAGORN, a program to detect tRNA genes and tmRNA genes in nucleotide sequences. Nucleic Acids Res. 2004, 32, 11-16. [CrossRef]

41. ARAGORN Detects TRNA, MtRNA and TmRNA Genes. Available online: http://www.ansikte.se/ARAGORN/ (accessed on 31 May 2021).

42. Garneau, J.R.; Depardieu, F.; Fortier, L.-C.; Bikard, D.; Monot, M. PhageTerm: A tool for fast and accurate determination of phage termini and packaging mechanism using next-generation sequencing data. Sci. Rep. 2017, 7, 1-10. [CrossRef]

43. Galaxy Pasteur. Available online: https://galaxy.pasteur.fr/?tool_id=toolshed.pasteur.fr $\% 2 F r e p o s \% 2 F f m a r e u i l \% 2 F p h a g e t e r m \%$ 2FPhageTerm\%2F1.0.12\&version=1.0.12\&_identifer=maucuexyo4 (accessed on 31 May 2021).

44. Darling, A.C.E.; Mau, B.; Blattner, F.R.; Perna, N.T. Mauve: Multiple Alignment of Conserved Genomic Sequence with Rearrangements. Genome Res. 2004, 14, 1394-1403. [CrossRef]

45. Thompson, J.D.; Higgins, D.G.; Gibson, T.J. CLUSTAL W: Improving the Sensitivity of Progressive Multiple Sequence Alignment through Sequence Weighting, Position-Specific Gap Penalties and Weight Matrix Choice. Nucleic Acids Res. 1994, 22, 4673-4680. [CrossRef] [PubMed]

46. Kumar, S.; Stecher, G.; Li, M.; Knyaz, C.; Tamura, K. MEGA X: Molecular Evolutionary Genetics Analysis across Computing Platforms. Mol. Biol. Evol. 2018, 35, 1547-1549. [CrossRef]

47. Savalia, D.; Westblade, L.F.; Goel, M.; Florens, L.; Kemp, P.; Akulenko, N.; Pavlova, O.; Padovan, J.C.; Chait, B.T.; Washburn, M.; et al. Genomic and Proteomic Analysis of phiEco32, a Novel Escherichia coli Bacteriophage. J. Mol. Biol. 2008, 377, 774-789. [CrossRef] [PubMed] 
48. Attoui, H.; Mertens, P.P.C.; Becnel, J.; Belaganahalli, S.; Bergoin, M.; Brussaard, C.P.; Chappell, J.D.; Ciarlet, M.; del Vas, M.; Dermody, T.S.; et al. Reoviridae. In Virus Taxonomy. Ninth Report of the International Committee on Taxonomy of Viruses, 1st ed.; King, A.M.Q., Adams, M.J., Carstens, E.B., Lefkowitz, E.J., Eds.; Elsevier Academic Press: London, UK, 2012 ; pp. 541-637. ISBN 978-012-384-684-6.

49. Mirzaei, M.K.; Eriksson, H.; Kasuga, K.; Haggård-Ljungquist, E.; Nilsson, A.S. Genomic, Proteomic, Morphological, and Phylogenetic Analyses of vB_EcoP_SU10, a Podoviridae Phage with C3 Morphology. PLoS ONE 2014, 9, e116294. [CrossRef] [PubMed]

50. Holt, A.; Saldana, R.; Moreland, R.; Gill, J.J.; Liu, M.; Ramsey, J. Complete Genome Sequence of Escherichia coli Phage Paul. Microbiol. Resour. Announc. 2019, 8, e01093-19. [CrossRef]

51. Mirzaei, M.K.; Nilsson, A.S. Correction: Isolation of Phages for Phage Therapy: A Comparison of Spot Tests and Efficiency of Plating Analyses for Determination of Host Range and Efficacy. PLoS ONE 2015, 10, e0127606. [CrossRef] [PubMed]

52. Jurczak-Kurek, A.; Gąsior, T.; Nejman-Faleńczyk, B.; Bloch, S.; Dydecka, A.; Topka, G.; Necel, A.; Jakubowska-Deredas, M.; Narajczyk, M.; Richert, M.; et al. Biodiversity of bacteriophages: Morphological and biological properties of a large group of phages isolated from urban sewage. Sci. Rep. 2016, 6, 34338. [CrossRef]

53. Kleppen, H.P.; Holo, H.; Jeon, S.-R.; Nes, I.F.; Yoon, S.-S. Novel Podoviridae Family Bacteriophage Infecting Weissella cibaria Isolated from Kimchi. Appl. Environ. Microbiol. 2012, 78, 7299-7308. [CrossRef] [PubMed]

54. Matsushita, K.; Uchiyama, J.; Kato, S.-I.; Ujihara, T.; Hoshiba, H.; Sugihara, S.; Muraoka, A.; Wakiguchi, H.; Matsuzaki, S. Morphological and genetic analysis of three bacteriophages ofSerratia marcescensisolated from environmental water. FEMS Microbiol. Lett. 2009, 291, 201-208. [CrossRef]

55. Iwashita, S.; Kanegasaki, S. Smooth specific phage adsorption: Endorhamnosidase activity of tail parts of P22. Biochem. Biophys. Res. Commun. 1973, 55, 403-409. [CrossRef]

56. Bertozzi Silva, J.; Storms, Z.; Sauvageau, D. Host receptors for bacteriophage adsorption. FEMS Microbiol. Lett. 2016, 363, fnw002. [CrossRef] [PubMed]

57. Kortright, K.E.; Chan, B.K.; Turner, P.E. High-throughput discovery of phage receptors using transposon insertion sequencing of bacteria. Proc. Natl. Acad. Sci. USA 2020, 117, 18670-18679. [CrossRef]

58. Li, Y.; Huang, J.; Wang, X.; Xu, C.; Han, T.; Guo, X. Genetic Characterization of the O-Antigen and Development of a Molecular Serotyping Scheme for Enterobacter cloacae. Front. Microbiol. 2020, 11, 727. [CrossRef] [PubMed]

59. Xie, Y.; Wahab, L.; Gill, J.J. Development and Validation of a Microtiter Plate-Based Assay for Determination of Bacteriophage Host Range and Virulence. Viruses 2018, 10, 189. [CrossRef] [PubMed]

60. Hyman, P.; Abedon, S.T. Chapter 7-Bacteriophage Host Range and Bacterial Resistance. In Advances in Applied Microbiology; Academic Press: Salt Lake City, UT, USA, 2010; Volume 70, pp. 217-248.

61. Ross, A.; Ward, S.; Hyman, P. More Is Better: Selecting for Broad Host Range Bacteriophages. Front. Microbiol. $2016,7,1352$. [CrossRef]

62. Albers, S.; Czech, A. Exploiting tRNAs to Boost Virulence. Life 2016, 6, 4. [CrossRef]

63. Kropinski, A.; Nilsson, A.; Ackermann, H.; Lavigne, R.; Kuhn, J.; Adriaenssens, E. To Include Four (4) New Species within the Genus Phieco32virus in the Family Podoviridae; International Committee for Taxonomy of Viruses (ICTV) Proposal (Taxoprop) No. 2015.014aB; International Committee for Taxonomy of Viruses (ICTV): London, UK, 2015. [CrossRef]

64. Yang, H.; Ma, Y.; Wang, Y.; Yang, H.; Shen, W.; Chen, X. Transcription regulation mechanisms of bacteriophages. Bioengineered 2014, 5, 300-304. [CrossRef] 